\title{
Pregnancies Outcome after Assisted Reproductive Technology: A Multicenter Case Control Study in a Low Income Setting Douala, Cameroon
}

\author{
Tchente Nguefack Charlotte ${ }^{1,2 *}$, Bourdanne Tekouake Didier ${ }^{1}$, T. Nana Njamen ${ }^{2,3}$, \\ Nda Mefo'o Jean Pierre',4, Ekono Michel Roger ${ }^{1}$, Essome Henri' ${ }^{1}$, Tsingaing Kamgaing Jacques ${ }^{5}$, \\ Gwet Bell Ernestine ${ }^{6}$, Sandjon Guy7, Halle Ekane Edie Gregory ${ }^{2,3}$
}

${ }^{1}$ Faculty of Medicine and Pharmaceutical Science, University of Douala, Douala, Cameroon

${ }^{2}$ Department of Gynecology and Obstetrics, Douala General Hospital, Douala, Cameroon

${ }^{3}$ Faculty of Health Sciences, University of Buea, Buea, Cameroon

${ }^{4}$ Department of Biology, Douala General Hospital, Douala, Cameroon

${ }^{5}$ Bel Air Plus Clinic Douala, Douala, Cameroon

${ }^{6}$ Odyssée Medical Clinic Douala, Douala, Cameroon

${ }^{7}$ Clinique de l'Aéroport Douala, Douala, Cameroon

Email: *cnguefack2007@yahoo.fr

How to cite this paper: Charlotte, T.N., Didier, B.T., Njamen, T.N., Pierre, N.M.J., Roger, E.M., Henri, E., Jacques, T.K., Ernestine, G.B., Guy, S. and Gregory, H.E.E. (2021) Pregnancies Outcome after Assisted Reproductive Technology: A Multicenter Case Control Study in a Low Income Setting Douala, Cameroon. Open Journal of Obstetrics and Gynecology, 11, 720-731. https://doi.org/10.4236/ojog.2021.116067

Received: May 7, 2021

Accepted: June 15, 2021

Published: June 18, 2021

Copyright $\odot 2021$ by author(s) and Scientific Research Publishing Inc. This work is licensed under the Creative Commons Attribution International License (CC BY 4.0).

http://creativecommons.org/licenses/by/4.0/ (c) (i) Open Access

\begin{abstract}
The objective was to assess the outcome of pregnancies after assisted reproductive technology (ART). It was a case-control study carried out in four health facilities in Douala-Cameroon, over a period of five years. The cases were pregnant women who conceived through ART and the controls were those who conceived naturally. Cases and controls were matched for maternal age and parity (one case for two controls). A logistic regression analysis was used to compute Odds ratios. Statistical significance was set at 0.05 . A total of 174 women who conceived through ART and 348 who conceived naturally were enrolled. Some independent factors associated with ART were: age over 45 years [aOR: 7.55 ; 95\% CI (1.55 - 36.76); p: 0.01], twin pregnancies [aOR: 16.55; 95\% CI (7.91 - 34.60); $\mathrm{p}<0.01$ ], Cervical cerclage [aOR: 3.04; 95\% CI (1.23 - 7.50); p: 0.01], miscarriages [aOR: 11.73; 95\% CI (5.07 - 27.10); p: 0.01 ], elective cesarean section [aOR: 4.63; 95\% CI (2.27 - 9.45); p: 0.01] and low birth weight [aOR: 3.32; 95\% CI $(1.90-5.82)$; $<<0.01$ ]. Women who conceived by ART were older with higher rates of multiple pregnancy and complications. We recommend transfer of a single embryo.
\end{abstract}

\section{Keywords}

Pregnancy Outcome, Assisted Reproductive Technology, Douala 


\section{Introduction}

The prevalence of infertility is high both in high income countries (5\% to 10\%) and limited resources countries (15\% to 30\%) [1] [2] [3]. In Sub-Saharan Africa, especially in central Africa, its rate is high [3] [4]. In Cameroon, $20 \%$ to $30 \%$ of couples suffer from infertility and the prevalence varies from one region to another [4]. The management of infertility involves ART which includes a wide spectrum of treatments. The first baby conceived through in vitro fertilization (IVF) was born in 1978. Since then, 5.4 million children have been conceived through ART worldwide [5]. More than half of the global ART is carried out in Europe. In France, one child in thirty-two would be born through ART. In United States, children conceived by ART represent $1.7 \%$ of the total number of births [6]. In sub-Saharan Africa, the ART is not readily accessible due to the high cost meanwhile the prevalence of infertility is high [7]. To afford it, Couples save money for many years because the treatment is not covered by insurance in Cameroon. They all hope to have good results (baby at home).

Many studies have been carried out on the outcome of pregnancy after ART. Results revealed high risk of miscarriages, prematurity and fetal growth restriction (FGR) [8] [9]. Such complications are often due to the high rate of multiple pregnancies induced by ART [10]. However, in the case of single pregnancies, several meta-analyzes showed an excess risk of prematurity $(\mathrm{OR}=1.95$; CI 1.73 $2.20)$ and of FGR (OR = 1.60; CI 1.25 - 2.04) compared to naturally conceived pregnancies [11] [12]. An increased risk of pre-eclampsia (OR = $1.55 \mathrm{CI} 1.23$ 1.95) was also found [13]. A rate of $2.2 \%$ of ectopic pregnancy after IVF and $1.8 \%$ after natural conception was reported in USA [14]. In Douala in 2016 it was found that IVF increased the risk of multiple pregnancies and cesarean delivery by 7.5 and by 4.1 compared to spontaneous pregnancies [15]. Pregnancy conceived by ART therefore appears to be associated with an increase perinatal morbidity. It is worth noting that, these results in Douala concerned one ART method (IVF) and where from a single center. However, there are 2 centers in Douala where almost all ART techniques are practiced necessitating an evaluation of the outcome of pregnancies after ART in these centers.

\section{Materials and Methods}

A case-control study was carried out from January $1^{\text {st }}, 2014$ to December 31, 2018. Participants were enrolled from four health facilities in Douala: Douala General Hospital, Bel Air Plus Clinic, Odyssée Medical Clinic (OMC) and Clinique de l'Aéroport (CDA). OMC and CDA being health facilities where ART is carried out. A case was a pregnant woman who conceived by ART (positive pregnancy test) and the control was the consecutive woman with positive pregnancy test coming for antennal consultation who conceived naturally. Cases and controls were matched for antenatal age and parity \pm 1 with a matching ratio of 1:2 for cases and controls respectively. Due to the rarity of spontaneous pregnancies from 43 years and above, the cases and controls of this age group were 
all matched together respecting the parity \pm 1 . ART techniques used in the 2 centers were IVF, Intracytoplasmic Sperm Injection (ICSI), insemination, ovarian stimulation without insemination, gametes donation especially in women aged 42 years or more or in men with azoospermia. Cryopreservation of sperm, oocytes, and embryos was also done, with embryo transfer later on. Preimplantation genetic diagnosis and gamete intrafallopian transfer (GIFT) are not offered in these centers.

\subsection{Data Collection}

The data of the participants were collected using standardized survey questionnaires and subsequently reviewed. These data were obtained from the ART unit files, antenatal care records, delivery and hospitalization records. The variables evaluated were; maternal age, marital status, religion, level of education, profession, Mode of conception (spontaneous or by ART), medical and surgical past history, gynecological and obstetrical history, pregnancy course and antenatal complications, mode of delivery, complications during labor and the status of the infant at birth. Surrogate mother files were excluded.

\subsection{Ethical Clearance}

Ethical clearance was obtained from the ethics committee of the University of Douala (№ 1681 CEI-Udo 02/2019/T) and authorization from the directors of the study health facilities was granted. The study was carried out with respect of the fundamental principles of medical research.

\subsection{Data Analysis}

Data were recorded and processed using Statistical software EPI info version 3.4.5. Quantitative variables were expressed as mean $\pm \mathrm{SD}$ and qualitative variables were expressed as numbers with percentages. In the univariate analysis, qualitative variables (outcomes of pregnancies conceived by ART or naturally) were compared using the chi-squared or Fisher exact test for dichotomous variables. Quantitative variables were compared using the Student $t$ test. Statistical significance was set at $\mathrm{p}<0.05$. Multivariate logistic regression was used to determine factors that were independently associated with outcome of pregnancy after ART. Variables with $\mathrm{p} \leq 0.08$ in univariate analysis were included in the model.

\section{Results}

The mean age was $37.9 \pm 6.1$ years for cases (range $24-56$ ) and $37.3 \pm 5.2$ for controls (range 24 - 47). Age group $>45$ years (OR: 8.71), business as profession (OR: 2.39), marital status (OR: 2.63), high level education (OR: 1.67) and Catholic religion (OR: 2.12) were significant associated factors to ART ( $<<0.01)$ (Table 1).

Intra cytoplasmic Sperm Injection (ICSI) with transfer of fresh embryo was the most common used technique (Table 2). 
Table 1. Socio-demographic characteristics of studied population.

\begin{tabular}{|c|c|c|c|c|c|}
\hline & Case & control & Total & OR (CI 95\%) & P-value \\
\hline Variables & $\mathrm{n}=174(\%)$ & $\mathrm{n}=348(\%)$ & $\mathrm{N}=522(\%)$ & & \\
\hline \multicolumn{6}{|l|}{ Age } \\
\hline [24 - 30] & $23(13.2)$ & $46(13.2)$ & $69(13.2)$ & $1(0.58-1.70)$ & 0.550 \\
\hline [31 - 39] & $71(40.8)$ & $142(40.8)$ & $213(40.8)$ & $1(0.69-1.45)$ & 0.540 \\
\hline$[40-45]$ & $64(36.8)$ & $156(44.8)$ & $220(42.1)$ & $0.72(0.49-1.04)$ & 0.050 \\
\hline$>45$ & $16(9.2)$ & $4(1.1)$ & $20(3.8)$ & $8.71(3.00-30.63)$ & $<0.001$ \\
\hline \multicolumn{6}{|l|}{ Profession } \\
\hline Public sector & $57(32.8)$ & $96(27.6)$ & $153(29.3)$ & $1.28(0.86-1.9)$ & 0.130 \\
\hline Private sector & $57(32.8)$ & $121(34.8)$ & $178(34.1)$ & $0.91(0.62-1.34)$ & 0.360 \\
\hline Business & $33(19.0)$ & $31(8.9)$ & $64(12.3)$ & $2.39(1.4-4.07)$ & $<0.001$ \\
\hline Students & $13(7.5)$ & $24(6.9)$ & $37(7.1)$ & $1.09(0.53-2.19)$ & 0.470 \\
\hline House wife & $7(4.0)$ & $53(15.2)$ & $60(11.5)$ & $0.23(0.1-0.5)$ & $<0.001$ \\
\hline Small business & $7(4.0)$ & $23(6.6)$ & $30(5.7)$ & $0.59(0.23-1.37)$ & 0.160 \\
\hline \multicolumn{6}{|l|}{ Marital status } \\
\hline Maried & $145(83.3)$ & $228(65.5)$ & $373(71.5)$ & $2.63(1.68-4.2)$ & $<0.001$ \\
\hline Single & $29(16.7)$ & $120(34.5)$ & $149(28.5)$ & $0.38(0.24-0.6)$ & $<0.001$ \\
\hline \multicolumn{6}{|l|}{ Level of education } \\
\hline Secondary & $60(34.5)$ & $163(46.8)$ & $223(42.7)$ & $0.6(0.41-0.87)$ & $<0.001$ \\
\hline University & $114(65.5)$ & $185(53.2)$ & $299(57.3)$ & $1.67(1.15-2.45)$ & $<0.001$ \\
\hline \multicolumn{6}{|l|}{ Religion } \\
\hline Catholic & $134(77)$ & $213(61.2)$ & $347(66.5)$ & $2.12(1.41-3.23)$ & $<0.001$ \\
\hline Protestant & $32(18.4)$ & $101(29.0)$ & $133(25.5)$ & $0.55(0.35-0.86)$ & 0.010 \\
\hline Muslim & $2(1.1)$ & $7(2.0)$ & $9(1.7)$ & $0.57(0.08-2.58)$ & 0.380 \\
\hline Other religion & $6(3.4)$ & $26(7.5)$ & $32(6.1)$ & $0.44(0.16-1.06)$ & 0.050 \\
\hline
\end{tabular}

OR: Odds ratio; CI: Confidence interval.

Table 2. Methods of assisted reproductive technology.

\begin{tabular}{|c|c|c|}
\hline ART methods & Number & $\%$ \\
\hline Ovulation induction & 004 & 2.3 \\
\hline Artificial insemination with male partner's semen & 006 & 3.4 \\
\hline Donor insemination & 004 & 2.3 \\
\hline In-vitro fertilisation with intra-conjugual fresh embryo transfer & 031 & 17.8 \\
\hline Intracytoplasmic sperm injection with fresh embryo transfer & 056 & 32.2 \\
\hline In-vitro fertilisation with donor ovocyte and fresh embryo transfer & 041 & 23.6 \\
\hline In-vitro fertilisation with donor sperm and fresh embryo transfer & 013 & 7.5 \\
\hline In-vitro fertilisation with donate fresh embryos and transfer & 007 & 4.0 \\
\hline In-vitro fertilisation with donate frozen embryos & 012 & 6.9 \\
\hline Total & 174 & 100 \\
\hline
\end{tabular}

ART: Assisted Reproductive Technology. 
ART increased the risk of twin pregnancy by $17.96[9.51-35.6](\mathrm{p}<0.001)$. We found 10 triple pregnancies (5.7\%) and 1 quadruple (0.6\%) exclusively in the case group. Compared to the trend in spontaneous pregnancies, increase threatening abortion and premature labor in the ART group was insignificant. ART multiplied the risk of cerclage by 4.15 . Pregnant women who conceived by ART had 8.2 times increased risk of early miscarriages (Table 3 ).

Women who conceived through ART had 1.97 fold higher odds of having preterm babies. The ART group had significantly high cesarean delivery rate (81\%) compared to the control group (40.8\%), $\mathrm{P}<0.001$; mainly elective caesarian section (Table 4). The most common indications were precious baby, advanced maternal age and multiple pregnancies.

Table 3. Pathologies and outcome of pregnancies.

\begin{tabular}{|c|c|c|c|c|c|}
\hline & Case & control & Total & OR (CI 95\%) & $\mathbf{P}$ \\
\hline Variables & $\mathrm{n}=114(\%)$ & $\mathrm{n}=175(\%)$ & $\mathrm{N}=289(\%)$ & & \\
\hline \multicolumn{6}{|c|}{ Hospitalisation } \\
\hline Yes & $106(60.9)$ & $109(31.3)$ & $215(41.2)$ & $3.42(2.34-5)$ & 0.000 \\
\hline No & $68(39.1)$ & $239(68.7)$ & $307(58.8)$ & & \\
\hline \multicolumn{6}{|l|}{ Vomiting } \\
\hline Yes & $7(6.1)$ & $1(0.6)$ & $8(2.8)$ & $11.38(1.71-259.8)$ & 0.010 \\
\hline No & $107(93.9)$ & $174(99.4)$ & $281(97.2)$ & & \\
\hline \multicolumn{6}{|c|}{ Urinary tract Infection } \\
\hline Yes & $15(13.3)$ & $38(21.7)$ & $53(18.4)$ & $0.55(0.28-1.05)$ & 0.050 \\
\hline No & $98(86.7)$ & $137(78.3)$ & $235(81.6)$ & & \\
\hline \multicolumn{6}{|c|}{ Gestational diabetes } \\
\hline Yes & $5(4.4)$ & $6(3.4)$ & $11(3.8)$ & $1.29(0.35-4.53)$ & 0.450 \\
\hline No & $109(95.6)$ & $169(96.6)$ & $278(96.2)$ & & \\
\hline \multicolumn{6}{|c|}{ Hypertension in pregnancy } \\
\hline Yes & $9(7.89)$ & $12(6.85)$ & $21(7.26)$ & $1.36(0.23-2.88)$ & 0.310 \\
\hline No & $105(92.11)$ & $163(93.15)$ & $234(92.74)$ & & \\
\hline \multicolumn{6}{|c|}{ Placenta Prævia } \\
\hline Yes & $5(4.4)$ & $11(6.3)$ & $16(5.5)$ & $0.68(0.21-2)$ & 0.340 \\
\hline No & $109(95.6)$ & $164(93.7)$ & $273(94.5)$ & & \\
\hline \multicolumn{6}{|l|}{ TA/TPD* } \\
\hline Yes & $74(64.9)$ & $70(40)$ & $144(49.8)$ & $2.78(1.7-4.54)$ & 0.000 \\
\hline No & $40(35.1)$ & $105(60)$ & $145(50.2)$ & & \\
\hline \multicolumn{6}{|c|}{ Early Miscarriage } \\
\hline Yes & $42(24.1)$ & $13(3.7)$ & $55(10.5)$ & $8.2(4.31-16.22)$ & $<0.001$ \\
\hline No & $132(75.9)$ & 47 (89.5) & $467(89.5)$ & & \\
\hline \multicolumn{6}{|c|}{ Cervical cerclage } \\
\hline Yes & $45(25.9)$ & $27(7.8)$ & $72(13.8)$ & $4.15(2.47-7.02)$ & $<0.001$ \\
\hline No & $129(74.1)$ & $321(92.2)$ & $450(86.2)$ & & \\
\hline
\end{tabular}

OR: Odds ratio; CI: Confidence interval; TA/TPD: Threaten Abortion/Threaten Preterm Delivery. 
Table 4. Term and mode of delivery.

\begin{tabular}{|c|c|c|c|c|c|}
\hline & Case & Control & Total & OR $(95 \% \mathrm{CI})$ & P-value \\
\hline Variables & $\mathrm{n}=174(\%)$ & $\mathrm{n}=348(\%)$ & $\mathrm{N}=522(\%)$ & & \\
\hline \multicolumn{6}{|l|}{ Term at delivery } \\
\hline \multicolumn{6}{|l|}{$[28-32[$} \\
\hline Yes & $9(5.2)$ & $18(5.2)$ & $27(5.2)$ & $1(0.42-2.26)$ & 0.570 \\
\hline No & $165(94.8)$ & $330(94.8)$ & $495(94.8)$ & & \\
\hline \multicolumn{6}{|l|}{ [32 - 37[ } \\
\hline Yes & $33(19.0)$ & $37(10.6)$ & $70(13.4)$ & $1.97(1.17-3.28)$ & 0.010 \\
\hline No & $141(81.0)$ & $311(89.4)$ & $452(86.6)$ & & \\
\hline \multicolumn{6}{|l|}{ [37 - 41[ } \\
\hline Yes & $81(46.6)$ & $260(74.7)$ & $341(65.3)$ & $0.29(0.20-0.43)$ & $<0.001$ \\
\hline No & $93(53.4)$ & $88(25.3)$ & $181(34.7)$ & & \\
\hline \multicolumn{6}{|l|}{$>41$} \\
\hline Yes & $0(0.0)$ & $1(0.3)$ & $1(0.2)$ & $0(0.00-38.00)$ & 0.670 \\
\hline No & $174(100.0)$ & 347 (99.7) & $521(99.8)$ & & \\
\hline Mode of delivery & $\mathrm{n}=121$ & $\mathrm{n}=316$ & $\mathrm{~N}=437$ & & \\
\hline Vaginal delivery & $23(19)$ & $187(59.2)$ & $210(48.1)$ & $0.16(0.1-0.27)$ & $<0.001$ \\
\hline Cesarean delivery & $98(81)$ & $129(40.8)$ & $227(51.9)$ & $618(3.74-10.38)$ & $<0.001$ \\
\hline Type of C/S* & $\mathrm{n}=98$ & $\mathrm{n}=129$ & $\mathrm{~N}=227$ & & \\
\hline Elective & $72(73.5)$ & $63(48.8)$ & $135(59.5)$ & $5.9(3.73-9.32)$ & $<0.001$ \\
\hline Emergency $\mathrm{C} / \mathrm{S}^{*}$ & $26(26.5)$ & $66(51.2)$ & $92(40.5)$ & $1.04(0.61-1.72)$ & 0.490 \\
\hline
\end{tabular}

OR: Odds ratio; CI: Confidence interval; $\mathrm{C} / \mathrm{S}^{*}$ : Cesarean section.

Concerning fetal outcomes, participants in the ART group had a higher incidence of birth weight less than 1500 grams and weight between 1500 - 2500 grams compared to the naturally conceived group. The 10-min Apgar scores were similar in both groups but 1st and 5 min Apgar scores were better in the group of participants with spontaneous pregnancies (Table 5).

In multiple regression analysis, women with ART were at greater risk of having twin pregnancy (adjusted Odd ratio (aOR): 16.55 [CI: 7.92 - 34.60]; $\mathrm{p}<$ 0.001), been hospitalized (aOR: 2.09 [CI: $1.01-4.29$ ]; p: 0.0456), having more than 10 antenatal cares (aOR: 6.57 [CI: 1.79 - 24.07]; p: 0.0045), cervical cerclage (aOR: 3.05 [CI: 1.55 - 36.8]; p: 0.0156), miscarriages (aOR: 11.73 [CI: 5.08 27.10]; $\mathrm{p}<0.001$ ), elective caesarean section (aOR: 4.64 [CI: 2.27 - 9.46]; $\mathrm{P}<$ 0.001 ) and low birth weight (aOR: 3.33 [CI: 1.90 - 5.82]; p < 0.001).

Concerning the socio-demographic characteristics, the following factors were independently associated with ART: advanced age (aOR: 7.55 [1.55 - 36.8]; p: 0.0123), business profession (aOR: 3.28 [1.34 - 8.03]; p: 0.0092), married status (aOR: 3.57 [1.82 - 7.01]; p: 0.0002), higher education level (aOR: 3.13 [1.65 5.92]; p: 0.0005). 
Table 5. Outcome of the new born.

\begin{tabular}{|c|c|c|c|c|c|}
\hline & Case & Control & Total & OR (CI 95\%) & $P$-value \\
\hline Variables & $\mathrm{n}=184(\%)$ & $\mathrm{n}=324(\%)$ & $\mathrm{n}=508(\%)$ & & \\
\hline \multicolumn{6}{|l|}{ Weight } \\
\hline$<1500$ & $10(5.2)$ & $6(1.8)$ & $16(3.1)$ & $2.95(1.05-8.86)$ & 0.030 \\
\hline$[1500-2500[$ & $60(31.1)$ & $40(12.1)$ & $100(19.1)$ & $3.27(2.08-5.14)$ & $<0.001$ \\
\hline$[2500-4000[$ & $111(57.5)$ & $258(78.2)$ & $369(70.6)$ & $0.38(0.26-0.56)$ & $<0.001$ \\
\hline$\geq 4000$ & $3(1.6)$ & $20(6.1)$ & $23(4.4)$ & $0.24(0.06-0.77)$ & 0.010 \\
\hline \multicolumn{6}{|l|}{ Sex } \\
\hline Male & $77(39.9)$ & $140(42.4)$ & $217(41.5)$ & $0.9(0.63-1.29)$ & 0.320 \\
\hline Female & $107(55.4)$ & $184(55.8)$ & $291(55.6)$ & $0.99(0.69-1.41)$ & 0.510 \\
\hline \multicolumn{6}{|c|}{ Apgar $1^{\text {st }}$ Minute } \\
\hline$[0-3]$ & $1(0.5)$ & $5(1.5)$ & $6(1.1)$ & $0.34(0.01-2.47)$ & 0.280 \\
\hline$[4-7]$ & $56(29)$ & $66(20)$ & $122(23.3)$ & $1.64(1.08-2.47)$ & 0.010 \\
\hline$[8-10]$ & $127(65.8)$ & $253(76.7)$ & $380(72.7)$ & $0.59(0.4-0.87)$ & 0.010 \\
\hline \multicolumn{6}{|c|}{ Apgar $5^{\text {th }}$ Minute } \\
\hline$[0-3]$ & $0(0)$ & $2(0.6)$ & $2(0.4)$ & $0(0-5.94)$ & 0.400 \\
\hline$[4-7]$ & $29(15)$ & $25(7.6)$ & $54(10.3)$ & $2.16(1.22-3.83)$ & 0.010 \\
\hline$[8-10]$ & $155(80.3)$ & $297(90)$ & $452(86.4)$ & $0.45(0.27-0.75)$ & $<0.001$ \\
\hline \multicolumn{6}{|c|}{ Apgar $10^{\text {th }}$ Minute } \\
\hline$[0-3]$ & $1(0.5)$ & $1(0.3)$ & $2(0.4)$ & $1.71(0.04-67.02)$ & 0.600 \\
\hline$[4-7]$ & $3(1.6)$ & $5(1.5)$ & $8(1.5)$ & $1.03(0.2-4.49)$ & 0.620 \\
\hline$[8-10]$ & $180(93.3)$ & $318(96.4)$ & $498(95.2)$ & $0.52(0.23-1.19)$ & 0.080 \\
\hline \multicolumn{6}{|l|}{ Outcome } \\
\hline Alive & $157(78.8)$ & $308(93.3)$ & $465(88)$ & $0.26(0.15-0.46)$ & $<0.001$ \\
\hline Death & $27(13.5)$ & $16(4.8)$ & $43(8)$ & $3.06(1.59-5.96)$ & $<0.001$ \\
\hline
\end{tabular}

OR: Odds ratio; CI: Confidence interval.

\section{Discussion}

Intracytoplasmic sperm injection was the most used ART technique. Women who conceived by ART were older and had more complications like miscarriages and preterm deliveries than those who conceived naturally.

\subsection{Socio-Demographic Characteristics}

The average age of the population was similar to that of Belinga et al. in 2019 (37 \pm 8 years) in Yaoundé [16]. The main age group was $40-45$ years. The natural history of infertile woman in our environment justifies this advanced age: in general as long as they are young, they do not understand that they can be treated by ART. Sometimes, because of lack of finances and the false hope given by charlatans, couples seek medical treatment lately. Moreover, Cameroonian legislation does not limit the age access to ART. The average age was lower in 
other studies of the sub-region ( $33 \pm 4$ years) and higher in others $(43.7 \pm 3.5$ years) [17] [18].

Business women were more involved with the ART. Some authors have found similar results [15]. This could be explained by the fact that business offers sufficient financial autonomy since ART is usually inaccessible due to its cost and expenses incurred are not reimbursed by insurance companies in Cameroon.

Stable couples (living with the partner) are more likely to be involved in ART process as observed in this study. The same observation was made by Silva et al. in 2019 in Brazil, Egbe et al. in 2016 in Douala [15] [19]. The decision to start ART process may be easier for couples than for singles.

\subsection{Maternal Outcome}

ART was associated with increased risks of vomiting; threaten abortion and preterm delivery which could be due to the high frequency of multiple pregnancies in this group. Our results corroborate those of Kallen et al. who had found an increase in maternal pathologies in pregnancy in case of IVF [20].

Hypertension in pregnancy did not differ in the 2 groups. These results differ from other studies which showed an increased risk of hypertension in pregnancy in the event of single pregnancy resulting from ART [11] [13]. Our results could be due to the fact that, groups were matched for age and parity which are risk factors for hypertension in pregnancy.

Contrary to the result of meta-analysis of Jackson et al. who observed an increase of gestational diabetes in pregnancy by ART [11], we found similar incidences in the two groups. Our conclusion is similar to that of Schieve et al. who found no difference in the incidences of gestational diabetes in cases of spontaneous pregnancies and those after ART [21].

Cervical cerclage was most often realized in the ART group; the main indication being multiple pregnancy. Other authors found that performing a cervical cerclage is beneficial for the reduction of preterm birth and the prolongation of pregnancy in twin pregnancies with a cervical length of $<15 \mathrm{~mm}$ or dilated cervix of $>10 \mathrm{~mm}$. However, the benefit of this procedure in twin pregnancies with normal cervical length is not evidence based [22]. It may rather be a source of infection responsible for late miscarriages in our environment.

There was an association between ART and cesarean delivery. Egbe et al. and Kallen et al. had similar results [7] [20]. In Jackson's meta-analysis, there was an increased risk of planned cesarean section in participants who underwent ART [11]. The increased frequency of $\mathrm{C} / \mathrm{S}$ is more often due to multiple pregnancies, advanced maternal age, and increase frequency of preeclampsia. More often, we have increased stress of the obstetrician and the patient because of what is often termed "precious pregnancy", due to longer duration of infertility and amount of money spend for ART.

\subsection{Fetal Outcome}

In studied centers, usually 3 to 4 fresh embryos are transferred but recent studies 
have shown that the cumulative live birth rate is as good as or better with single embryo transfer over 2 cycles than with two embryos transferred in 1 cycle, while greatly reducing the probability of a multiple birth [23]. In our country there is no written law on ART. The transfer of embryos is then done arbitrarily and depends on the clinician and the patient's request. Although clinicians are aware of the risk of multiple pregnancies, they still allow themselves to transfer more embryos sometimes due to the financial difficulties that patients have to pay for ART. The rate of twin pregnancies in the ART group was similar to that reported in the literature and significantly differed from the control group. The CDC published the rate of twin or triplet pregnancy after ART of $46 \%$; Ikechebelu et al in Nigeria found $52.4 \%$ which was higher than the value found in our study (45.4\%) [6] [18]. There is need for our team to conform to current norms regarding number of embryos to be transferred.

Early spontaneous abortions are common complications of ART [8] [9] [18] [24]. However, some authors found that the high rate of miscarriage was mainly related to the risk factors of the patient, especially age. Pezeshki et al. found that infertile women who conceived after ART are not at increased risk for spontaneous abortion compared with women who conceived naturally [25]. The difference in the incidence of abortions in both groups persists after matching participant by age in our study. Our findings may be due to the fact that early miscarriage after natural conception are often diagnosed and managed in hospitals of lower category.

Assisted reproductive technology was associated with prematurity. Studies in large populations, including meta-analyzes had similar findings [6] [15] [21] [24]. This could be explained by the high frequency of multiple pregnancies associated to ART. However, in the case of single pregnancies, some meta-analyzes still showed the excess risk of prematurity compared to naturally conceived pregnancies [11].

The risk of low birth weight after ART is most often linked to the occurrence of multiple pregnancies. We found low birth weight as a factor associated with pregnancy after ART. Several authors have the same findings [6] [8] [9] [21] [24]. The low birth weight in this study could be explained by the high frequency of multiple pregnancies after ART (45.4\% versus 3.4\%). Furthermore, the effects of advanced maternal age need to be considered since many women who undergo ART are older thus being more likely to have pregnancy complications.

Several studies have reported an increase of perinatal mortality, including single pregnancies obtained by ART [6] [11]. In this study, there was an increase incidence of mortality in ART group compared to controls. Jackson et al. found a two fold increase risk in perinatal mortality in the ART group compared to their counterparts [11].

\section{Conclusion}

The following factors were independently associated with ART: advanced ma- 
ternal age, multiple pregnancies. ART increased obstetrical complications like spontaneous abortions, premature births, low birth weight, neonatal resuscitation and perinatal deaths. Cesarean delivery rate was significantly higher in ART group with elective cesarean deliveries indicated for "precious" pregnancy. Although these data were already reported, almost all were from developed countries. Data from developing countries are lacking thus the interest of the present study. We recommend reviewing the age of patients admitted for ART, making transfer of a single embryo and developing neonatal services.

\section{Study Limitations}

ART Protocols and antenatal care were not standardized in different centers. Groups were not matched according to the type of pregnancy (singleton or multiple) and gestational age.

\section{Acknowledgements}

We thank the administrators of the health facilities who allowed us to carry out the study.

\section{Authors' Contributions}

TNC, BD conceptualized the study. BD conducted the data collection, NJT, EMR, EH, TKJ, GBE and SG supervised the data collection. BD and NMJP conducted the data analysis. TNC and BD wrote the manuscript. HEEG supervised and proof read the manuscript. All the co-authors read and approved the final manuscript.

\section{Conflicts of Interest}

Authors do not declare any conflict of interest. The research was not funded.

\section{References}

[1] WHO (2020) Infertility Definitions and Terminology. https://www.who.int/reproductivehealth/topics/infertility/definitions/en

[2] Mascarenhas, M.N., Flaxman, S.R., Boerma, T., Vanderpoel, S. and Stevens, G.A. (2012) National, Regional, and Global Trends in Infertility Prevalence since 1990: A Systematic Analysis of 277 Health Surveys. PLOS Medicine, 9, e1001356. https://doi.org/10.1371/journal.pmed.1001356

[3] Larsen, U. (2000) Primary and Secondary Infertility in Sub-Saharan Africa. International Journal of Epidemiology, 29, 285-291. https://doi.org/10.1093/ije/29.2.285

[4] Larsen, U. (2003) Infertility in Central Africa. Tropical Medicine \& International Health, 8, 354-367. https://doi.org/10.1046/j.1365-3156.2003.01039.x

[5] Adamson, G.D., Macaluso, M., Tabangin, M. and de Mouzon, J. (2013) The Number of Babies Born Globally after Treatment with the Assisted Reproductive Technologies (ART). Fertility and Sterility, 100, S42. https://doi.org/10.1016/j.fertnstert.2013.07.1807

[6] Sunderam, S., Kissin, D.M., Crawford, S.B., Folger, S.G., Boulet, S.L., Warner, L. and 
Barfield, W.D. (2018) Assisted Reproductive Technology Surveillance-United States, 2015. MMWR Surveillance Summaries, 67, 1-28. https://doi.org/10.15585/mmwr.ss6703a1

[7] Omokanye, L.O., Olatinwo, A.O., Salaudeen, G.A., Durowade, K.A., Panti, A.A. and Balogun, R.O. (2018) Assisted Reproduction Technology in Nigeria: Challenges and the Way Forward. African Journal for Infertility and Assisted Conception, 3, 2-5. https://doi.org/10.4103/ajiac.ajiac 1 19

[8] Allen, V.M., Wilson, R.D., Cheung, A. and Genetics Committee (2006) Reproductive Endocrinology and Infertility Committee. Pregnancy Outcomes after Assisted Reproductive Technology. Journal of Obstetrics and Gynaecology Canada, 28, 220 233. https://doi.org/10.1016/S1701-2163(16)32112-0

[9] Tan, S.L., Doyle, P., Campbell, S., Beral, V., Rizk, B., Brinsden, P., Mason, B. and Edwards, R.G. (2002) Obstetric Outcome of in Vitro Fertilization Pregnancies Compared with Normally Conceived Pregnancies. American Journal of Obstetrics \& Gynecology, 167, 778-784. https://doi.org/10.1016/S0002-9378(11)91589-0

[10] American College of Obstetricians and Gynecologists, Committee Opinion No. 671 (Reaffirmed 2020), Committee on Obstetric Practice, Committee on Genetics (2016) Perinatal Risks Associated with Assisted Reproductive Technology.

https://www.acog.org/-/media/project/acog/acogorg/clinical/files/committee-opinio n/articles/2016/09/perinatal-risks-associated-with-assisted-reproductive-technology .pdf

[11] Jackson, R.A., Gibson, K.A., Wu, Y.W. and Croughan, M.S. (2004) Perinatal Outcomes in Singletons Following in Vitro Fertilization: A Meta-Analysis. Obstetrics \& Gynecology, 103, 551-563. https://doi.org/10.1097/01.AOG.0000114989.84822.51

[12] Qin, J., Liu, X., Sheng, X., Wang, H. and Gao, S. (2016) Assisted Reproductive Technology and the Risk of Pregnancy-Related Complications and Adverse Pregnancy Outcomes in Singleton Pregnancies: A Meta-Analysis of Cohort Studies. Fertility and Sterility, 105, 73-85.e1-6. https://doi.org/10.1016/j.fertnstert.2015.09.007

[13] Almasi-Hashiani, A., Omani-Samani, R., Mohammadi, M., Amini, P., Navid, B., Alizadeh, A., Morasae, E.K. and Maroufizadeh, S. (2019) Assisted Reproductive Technology and the Risk of Preeclampsia: An Updated Systematic Review and MetaAnalysis. BMC Pregnancy Childbirth, 19, Article No. 149. https://doi.org/10.1186/s12884-019-2291-x

[14] Clayton, H.B., Schieve, L.A., Peterson, H.B., Jamieson, D.J., Reynolds, M.A. and Wright, V. (2006) Ectopic Pregnancy Risk with Assisted Reproductive Technology Procedures. Obstetrics \& Gynecology, 107, 595-604. https://doi.org/10.1097/01.AOG.0000196503.78126.62

[15] Egbe, T.O., Sandjon, G., Ourtchingh, C., Simo, A., Priso, E.B. and Benifla, J.L. (2016) In-Vitro Fertilization and Spontaneous Pregnancies: Matching Outcomes in Douala, Cameroon. Fertility Research and Practice, 2, Article No. 1. https://doi.org/10.1186/s40738-015-0013-2

[16] Belinga, E., Noa Ndoua, C., Nyebe, F., Voundi, Voundi, E., Toukam, M., Ngono, V., Massin, N., Jimenez, C. and Kasia, J.M. (2019) The Outcome of Pregnancies Obtained after IVF Compared to Spontaneous Pregnancies at the Gynecological Endoscopic Surgery and Human Reproductive Teaching Hospital (GESHRTH). Clinical Obstetrics, Gynecology and Reproductive Medicine, 5, 1-4. https://doi.org/10.15761/COGRM.1000271

[17] Omokanye, L.O., Olatinwo, A.O., Saadu, L.O., Biliaminu, S.A., Durowade, K.A. and Panti, A.A. (2016) Assisted Reproductive Technology: Experience from a Public 
Tertiary Institution in North Central Nigeria. African Journal for Infertility and Assisted Conception, 1, 23-26.

[18] Ikechebelu, J.I., Eleje, G.U., Ibadin, K., Joe-Ikechebelu, N.N., Nwaefulu, K. and Okwelogu, S.I. (2016) Outcome of in Vitro Fertilization Procedure at a Private Fertility Center in Nnewi, South-East Nigeria. African Journal for Infertility and Assisted Conception, 1, 2-5. https://doi.org/10.4103/2468-8452.189960

[19] Silva, S.G., Da Bertoldi, A.D., Silveira, M.F., Da Domingues, M.R., Evenson, K.R. and Dos Santos, I.S. (2019) Assisted Reproductive Technology: Prevalence and Associated Factors in Southern Brazil. Revista de Saúde Pública, 53, 13. https://doi.org/10.11606/S1518-8787.2019053000737

[20] Källén, B. (2008) Maternal Morbidity and Mortality in In-Vitro Fertilization. Best Practice \& Research: Clinical Obstetrics \& Gynaecology, 22, 549-558.

https://doi.org/10.1016/j.bpobgyn.2008.02.001

[21] Schieve, L.A., Cohen, B., Nannini, A., Ferre, C., Reynolds, M.A., Zhang, Z., Jeng, G., Macaluso, M. and Wright, V.C. (2011) A Population-Based Study of Maternal and Perinatal Outcomes Associated with Assisted Reproductive Technology in Massachusetts. Maternal and Child Health Journal, 11, 517-525.

https://doi.org/10.1007/s10995-007-0202-7

[22] Li, C., Shen, J. and Hua, K. (2019) Cerclage for Women with Twin Pregnancies: A Systematic Review and Metaanalysis. American Journal of Obstetrics \& Gynecology, 220, 543-557. https://doi.org/10.1016/j.ajog.2018.11.1105

[23] Luke, B., Brown, M.B., Wantman, E., Stern, J.E., Baker, V.L., Widra, E., Coddington, C.C., Gibbons, W.E., Van Voorhis, B.J. and Ball, G.D. (2015) Application of a Validated Prediction Model for in Vitro Fertilization: Comparison of Live Birth Rates and Multiple Birth Rates with 1 Embryo Transferred over 2 Cycles vs 2 Embryos in 1 Cycle. American Journal of Obstetrics \& Gynecology, 212, 676.e1-7. https://doi.org/10.1016/j.ajog.2015.02.005

[24] Wang, A.Y., Safi, N., Ali, F., Lui, K., Li, Z., Umstad, M.P. and Sullivan, E.A. (2018) Neonatal Outcomes among Twins Following Assisted Reproductive Technology: An Australian Population-Based Retrospective Cohort Study. BMC Pregnancy Childbirth, 18, 320. https://doi.org/10.1186/s12884-018-1949-0

[25] Pezeshki, K., Feldman, J., Stein, D.E., Lobel, S.M. and Grazi, R.V. (2000) Bleeding and Spontaneous Abortion after Therapy for Infertility. Fertility and Sterility, 74, 504-508. https://doi.org/10.1016/S0015-0282(00)00707-X 